\title{
Development of Steam Distribution Network Simulation Program for Enhanced Oil Recovery
}

\author{
Ahmed Mahrous Norelden, Ahmed Safwat Nafey \\ Department of Engineering Sciences, Faculty of Petroleum and Mining Engineering, Suez University, Suez, Egypt
}

Email address:

Ahmed_mahros901@yahoo.com(A. M. Norelden)

\section{To cite this article:}

Ahmed Mahrous Norelden, Ahmed Safwat Nafey. Development of Steam Distribution Network Simulation Program for Enhanced Oil Recovery. Petroleum Science and Engineering. Vol. 2, No. 1, 2018, pp. 25-32. doi: 10.11648/j.pse.20180201.14

Received: March 23, 2018; Accepted: April 12, 2018; Published: May 14, 2018

\begin{abstract}
Steam injection networks are widely used in processes of Thermal Enhanced Oil Recovery (TEOR). It is desirable to maintain both the quality and flow rate of steam injected into the formation at certain specified values for optimum operation of the steam flood. This requires a surface distribution network designed to deliver uniform-quality steam to all wells. Unfortunately, unequal splitting of the liquid and vapor phases may occur at (tee junction) distribution network therefore Individual wells thus receive non-uniform and unknown distribution of the steam liquid and vapor. Unknown liquid and vapor phase distributions leads to inefficient project management, increased operating expenses and thereby detriment of the wells production. Simulation programs are important tools to monitor and evaluate steam distribution network. The main objective of this thesis is to develop a computer program to evaluate steam quality at well head of oil fields. Based on the Seeger model, a computer program for simulating the behavior of a large steam injection network was developed based on Mat Lab Graphical User Interface (GUI). Using this program a complete picture for the steam distribution network variables such as pressure, temperature and steam quality can be determined.
\end{abstract}

Keywords: Steam Distribution Network, T-junction, Two-Phase Flow, EOR

\section{Introduction}

Steam injection is the thermal method that add heat to the reservoir to expand the oil in-place, reduce oil viscosity, provide drive energy and thereby improve the displacement efficiency of injected fluid [1]. Crude-oil viscosity is inversely proportional to temperature. When the temperature increases, viscosity decreases. Less viscous oil results in greater mobility. Prats [2] indicated that the effect of steam injection on recovery is significantly greater as compared to hot-water injection. It is because steam carries more enthalpy per unit mass. The displacement of fluids by steam is selfstabilizing movement of the crude oil to the production well. Lake [3] emphasized that thermal methods, especially steam injection and steam soak, are easily the most successful enhanced oil recovery processes. Steam injection is widely applied to increase production. For the steam injection, several steam generators are located throughout the oil field to produce the steam that is fed into a distribution network. As the distribution network becomes more complex and larger. The steam flow becomes more complicated and the steam properties along the pipes vary greatly [4]. Thus, In order to predict steam properties in the distribution network with highly accuracy, it is necessary to understand the behavior of two-phase flow and splitting two-phase flow in the tee-junction to maintain optimum steam quality entering the reservoir.

Unfortunately, unequal splitting of the liquid and vapor phases can occur at (tee junction) distribution network therefore Individual wells thus receive non-uniform and unpredictable distribution of the steam liquid and vapor. Uneven liquid and vapor phase distribution results in poor displacement efficiency and volumetric sweep of the reservoir while unknown liquid and vapor phase distributions leads to inefficient project management and increased operating expenses. Therefore, it is important to develop a stimulating models, and methods to predict or control the qualities of the split streams.

In fact, T-junctions are commonly used components in piping systems as show in figure 1 . The behavior of dividing two-phase flow in a T-junction is critical in the design of the two-phase flow piping systems. When a two-phase flow is divided in a T-junctions, the branch and run qualities will, in 
general, differ from the inlet quality such a phenomenon is known as phase splitting [5]. In the case of the branching Tee, the phase splitting phenomena is generally more severe because the liquid phase of the two-phase fluid has high density and inertia and tends to flow straight through rather than making a $90^{\circ}$ turn. In other words, the branch stream tends to have a higher quality than that at the inlet while the run stream tends to have a quality less than that at the inlet. Furthermore, phase splitting also depends on the flow velocity, flow patterns, and quality of fluid at the inlet of the tee [6-7]. Over the years, there are general approaches have been used to describe the phase redistribution in T-junctions such as, experimental and numerical approaches. In this paper evaluated the empirical correlation models to simulate the behavior of a large steam injection network.

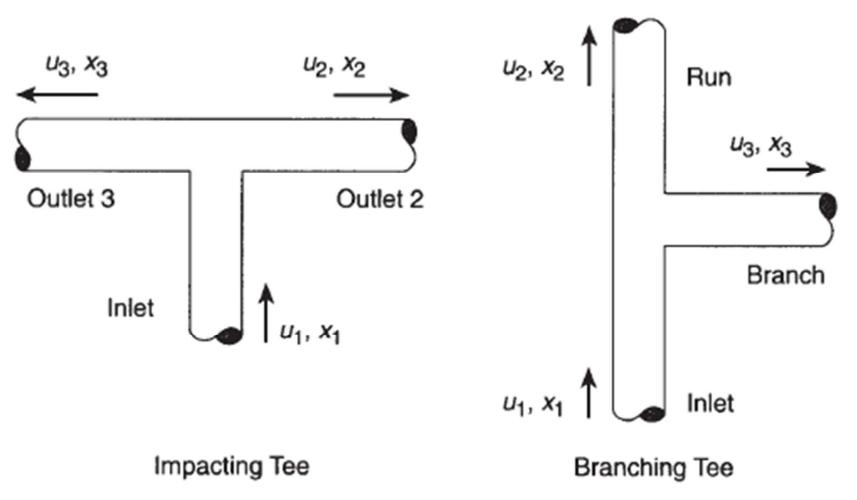

Figure 1. Tee Junction.

\section{Review of Literature}

A considerable amount of research has been conducted on the two-phase flow of dividing Tee junctions. Comprehensive researches can be found in the literature including Collier [8], Hong [9], Azzopardi \& Whalley [10], Seeger et al. [11], Lahey [12], Azzopardi and Hervieu [13], Azzopardi [14], Azzopardi \& Nicholson [15], and Baker \&Azzopardi [16]. These works demonstrated that the ratio of branch to inlet qualities $\mathrm{x} 3 / \mathrm{xl}$, which is indicative of phase distribution, is influenced by several parameters such as the inlet flow pattern, inlet quality $\mathrm{x} 1$, branch-to-inlet diameter ratio $\mathrm{D} 3 / \mathrm{D} 1$, branch orientation (from vertically up to vertically down) and extraction rate $\mathrm{W} 3 / \mathrm{W} 1$, where $\mathrm{W} 1$ and $\mathrm{W} 3$ are the inlet and branch mass flow rates, respectively. The large number of investigations is evidence of the importance and complexity of the problem. Most of this research was directed to the geometry of branching tees. In contrast, few studies are based on the geometry of the impacting Tee junction. It should be taken into consideration that the branching and impacting Tee junctions are treated almost independently in the literature regardless to the similarities between them.

These studies have concluded that the problem of phase distribution at branching junctions has not as yet been solved, no model is currently available with general applicability to all operating conditions. This is mainly due to the large number of variables on which phase distribution depends, such as junction geometry, fluid properties, inlet mass flow rate and quality, inlet flow regime, and mass split at the junction.

Wellhead steam quality is an important variable that determines thermodynamic properties of fluid. Among these properties which are important in evaluating steam injection process are specific volume and enthalpy. Doschar and Huang [17] conducted laboratory steam floods in a physical model to show that oil recovery vs. time increased with increasing steam quality. Experiments with a physical models showed that, at a constant mass injection rate, oil recovery increases with increasing steam quality. Based on the Marx-Langenheim model [18], The Boberg and Lontz [19] method estimates the oil production response during cyclic steam injection. Gomaa's [20] method can be used to predict steam oil ratio for steam flooding. All methods were based on steam quality and enthalpy in their procedures to calculate heat injection rate and heat effected zone in order to predict steam oil ratio.

\section{Phase Splitting Model Formulation}

In general, empirical correlations are used to deduce phase distribution in $\mathrm{T}$-junction. The process of creating the empirical equations for a certain application always requires an iterative experimentation work which is boring and expensive to perform. The empirical correlations are easy to use and the predicted results are usually reasonable if they are used in their appropriate range of conditions.

Seeger Model

Seeger et al. (1986) developed empirical correlations based on a large data bank for both air/water and steam/water flow with a horizontal inlet and equal inlet and branch diameters $(\mathrm{D} 1=\mathrm{D} 2=\mathrm{D} 3=50 \mathrm{~mm})$ covering the ranges of $500<\mathrm{G} 1<7500 \mathrm{~kg} / \mathrm{m}^{\wedge} 2 . \mathrm{s}, 0.002<\mathrm{X} 1<0.33,0.1<\mathrm{P} 1<10 \mathrm{MPa}$. They recommended empirical correlations for different branch orientations, i.e. horizontal, vertically upward and vertically downward.

For horizontal branch T-junction:

$$
\frac{X 3}{X 1}=5\left(\frac{U 3}{U 1}\right)-6\left(\frac{U 3}{U 1}\right)^{2}+2\left(\frac{U 3}{U 1}\right)^{3}+\mathrm{a}\left(\frac{U 3}{U 1}\right)\left(1-\frac{U 3}{U 1}\right)^{4}
$$

The parameter ' $a$ ' relates the peak of the phase separation curve, $(x 3 / x 1)$ max, to the ratio of the gas to liquid momentum flux $\left(\rho g \quad U g^{\wedge} 2 / \rho L \quad U L^{\wedge} 2\right)$ in the inlet Section. From their experiments, equal separation was approached as the ratio of momentum fluxes approaches unity. The value of 'a' was determined from an empirical fit of their data as, $a=14.6$ for bubbly flow and for all other flow patterns.

$$
\mathrm{a}=13.9\left[\left(\frac{v g 1}{v f 1 S 1^{2}}\right)^{0.26}-1\right]
$$

$\mathrm{S} 1$ is the ratio of the vapor-phase velocity to the liquidphase velocity. Its correlation as adapted from Rohani.4

$$
\mathrm{S} 1=\left\{[1+0.12(1-x 1)] v 1+\frac{V g 1}{U 1}-x 1 v g 1\right\} \frac{1}{(1-x 1) v f 1}
$$

Where $v 1$ is the specific volume of steam at the inlet of the 
tee and $\mathrm{Vg} 1$ is the weighted mean drift velocity of the vapor phase at the inlet of the tee,

$$
\overline{\mathrm{V}} \mathrm{g} 1=1.18 v f 1^{0.5}\left[\left[g \sigma\left(\frac{1}{v f 1}-\frac{1}{v g 1}\right]\right]^{0.25}\right.
$$

Seeger et al. presented, as shown in Figure 2, that the quality of the fluid existing the branch stream in a horizontal tee is generally higher than that entering the inlet. Based on the branching tee data obtained by Texaco, Rubel et al. evaluated the accuracy of several phase-splitting models for flow through branching tees. These included models proposed by Seeger et al., 3 Azzopardi and Whalley, Shoham et al., Hwang et al., and Hart et al. Seeger et al.'s model predicted closest to the experimental data, to within $+-30 \%$ for about $90 \%$ of Texaco's data.

The results of the horizontal branch showed preferential gas removal. Total separation was approached for high values of branch flow split. The branch quality generally peaked at flow splits (u3/u1 of approximately 0.3 ). Also it showed that an increase in inlet quality resulted in reducing the peak and the degree of the phase separation, $\mathrm{x} 3 / \mathrm{x} 1$, and increasing the flow split ratio $\mathrm{u} 3 / \mathrm{u} 1$.

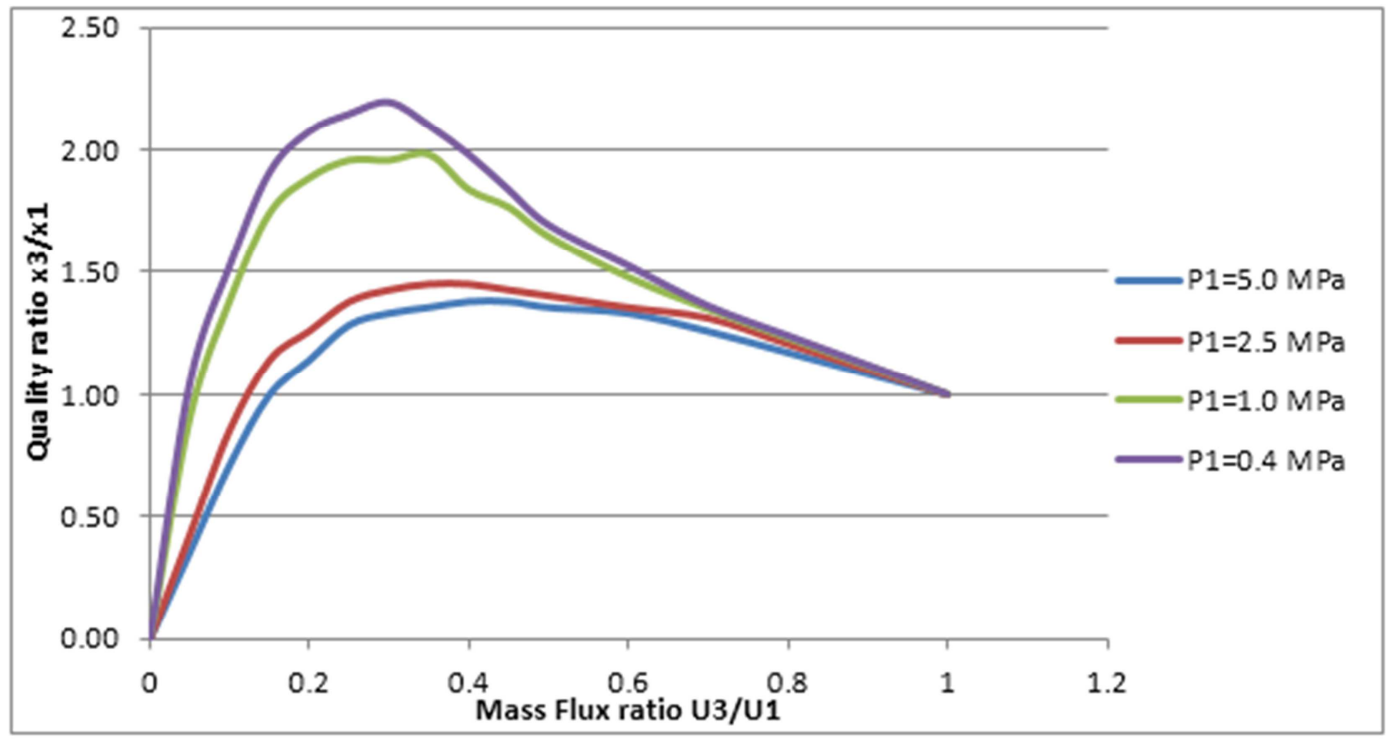

Figure 2. Seeger et al flow through a horizontal branching tee.

\section{Simulation Program for Network Quality Prediction}

To face a steam quality measure problem in the two-phase steam network. It became necessary to have a program installation able to record steam quality, temperature and pressure data across a whole steam network. Simple program have been designed based on MATLAB able to it. The program provides a dedicated user interface for operators to build the distribution network model easily and to visualize the simulation results. The program takes into account Tjunction effect on phase separation. Then the operators can build the distribution network model by major factors such as actual distance of pipes, individual well injection rate, pipes diameter, and number of wells etc. are defined by the operator inputs. The results can be visualized as a numeric form or a graphical form. The program adopted on Seeger model to descript phase separation in T-junction in steam distribution network.

\subsection{Graphical User Interface GUI of the Main Program}

The GUI is demonstrated with snapshot of the program. The first snapshot gives the background for the program. The second snapshot is about calculations for any steam network with take into account $\mathrm{T}$-junction effects with input parameters. The third snapshot is the output parameters for specified Steam network. The fourth and fifth snapshot is the output tables with ability to repeat calculations for selected branch. The sixth snapshot is about the post-processing for viewing the results in figures for steam quality, steam pressure, and steam temperature along the steam network.

First snapshot of the program is shown Figure 3, it is seen that there are several Input parameters for specially steamer outputs parameters for steam network. User can choose numbers of branches expressed by the number of $\mathrm{T}$ junctions. Figure 4 shows the diagram for main line of the network and the number of T-junction that existing in the steam distribution network. Figure 5 and Table 1 are shown results after the calculation done and user able to save those data to excel sheet. The user is able to restore the calculation at any branch containing more than $\mathrm{T}$-junction. Therefore could evaluate and design any steam distribution network through GUI that was explained. 


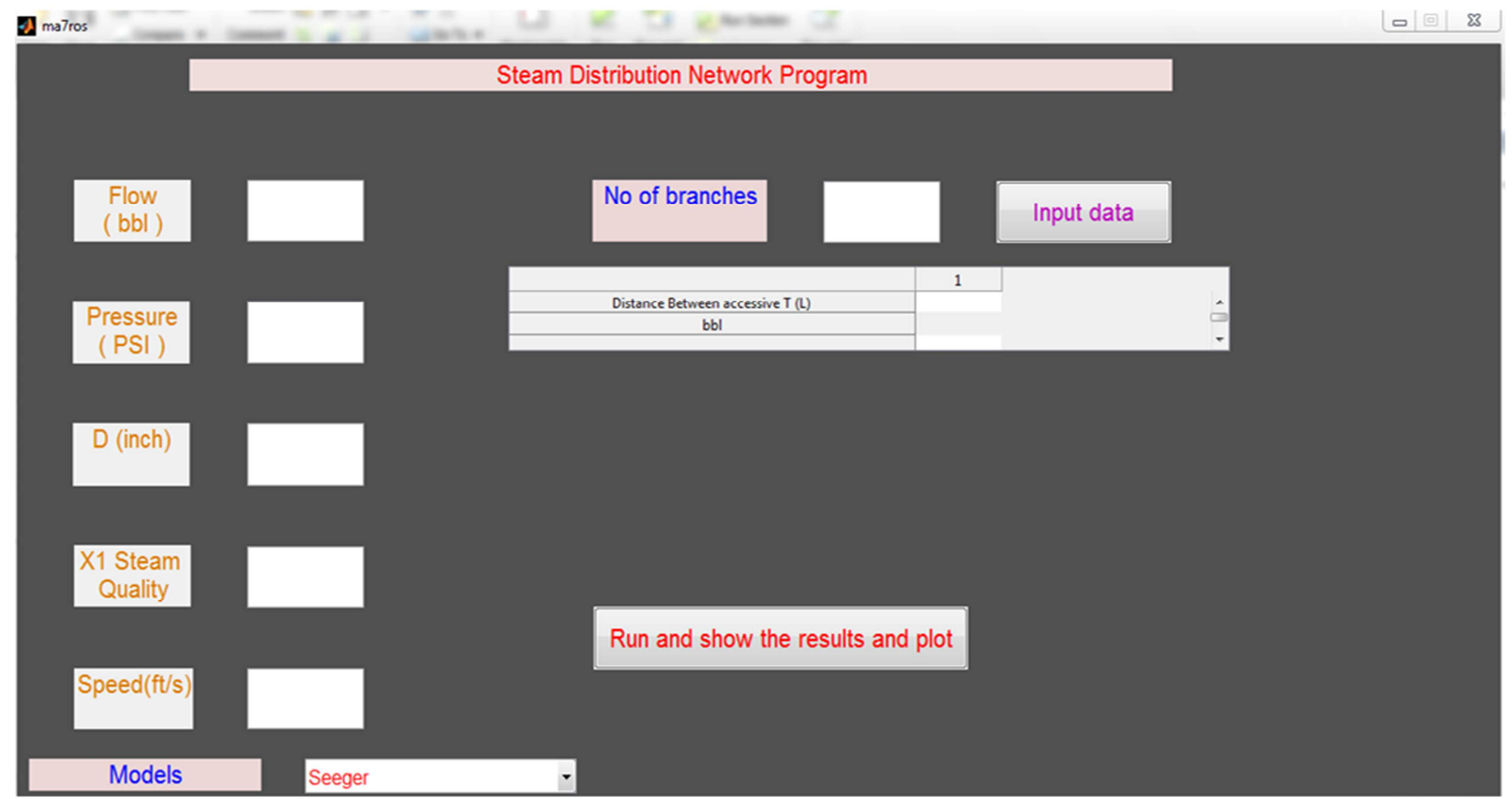

Figure 3. Graphical User interface input parameters.

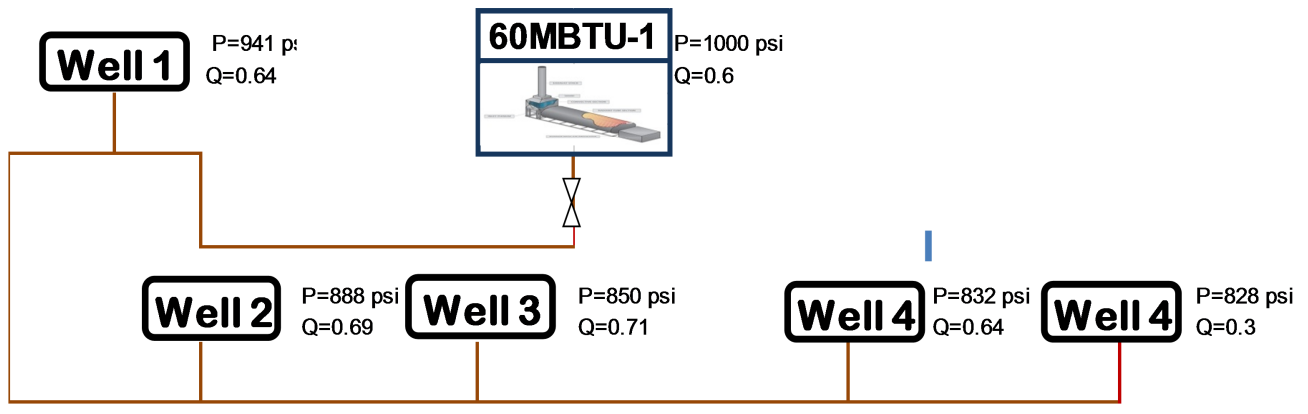

Figure 4. Graphical User interface for layout of main line and branches.

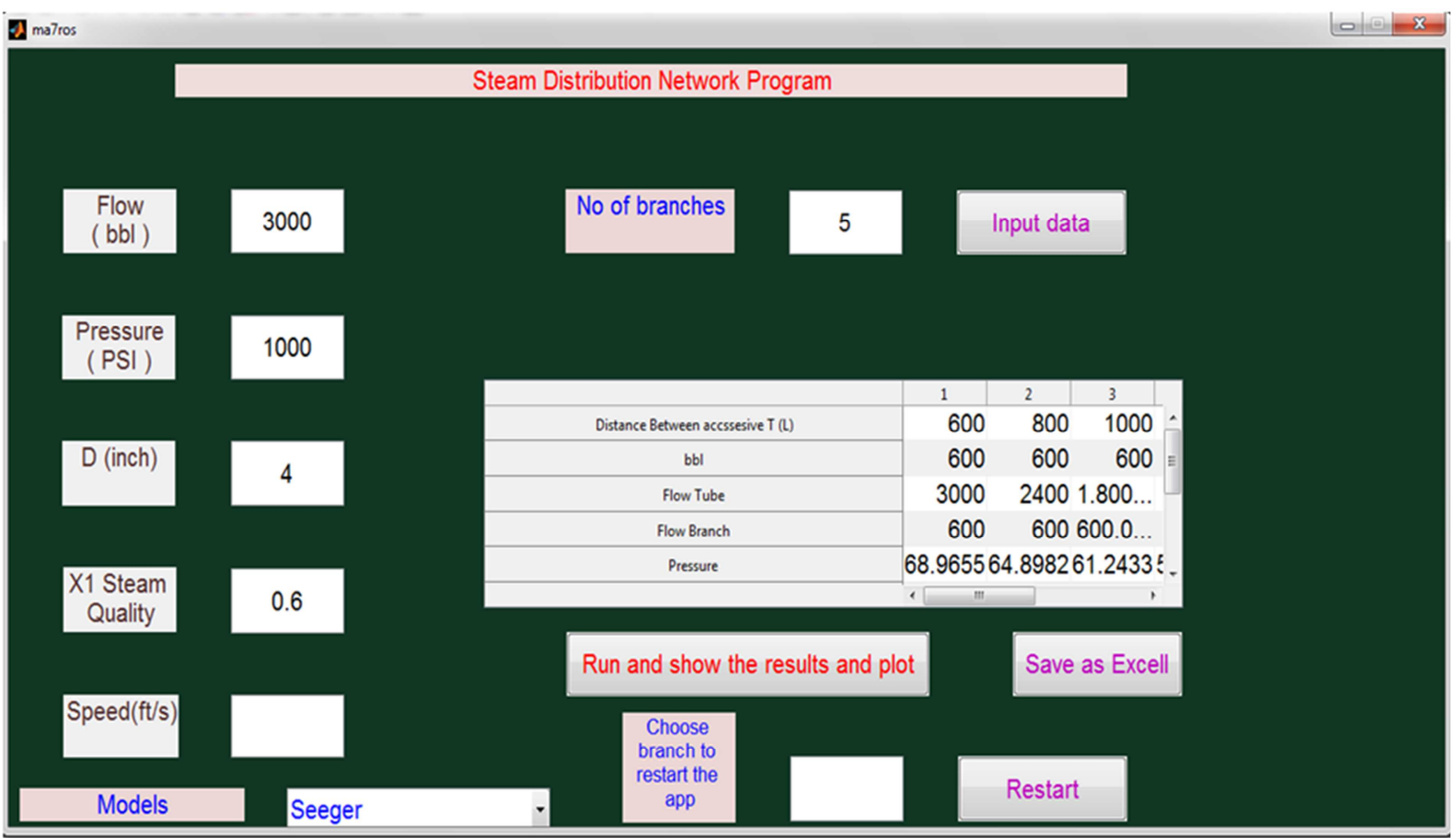

Figure 5. Graphical User interface after calculation with ability of restart calculation 
Table 1. Results shown as excel sheet.

\begin{tabular}{lllllll}
\hline Length (m) & Flow (bbl) & flow branch (bbl) & pressure (psi) & T1 & X1 Quality & X3 Quality \\
\hline 600 & 600 & 600 & 941 & 284 & 0.6 & 0.64 \\
800 & 600 & 600 & 888 & 280 & 0.58 & 0.69 \\
1000 & 600 & 600 & 850 & 276 & 0.55 & 0.71 \\
1200 & 600 & 600 & 828 & 273 & 0.47 & 0.64 \\
1400 & 600 & 600 & 272 & 0.3 & 0.3 \\
\hline
\end{tabular}

\subsection{Validation of Steam Distribution Network Program}

From the previous, illustrated that it possible develop a computer Program able to design or evaluate any steam distribution network based on Seeger model. To validate multiphase, looped network cases, comparisons are made to existing software with actual network (ISSRAN Oil Field).

\subsection{Experimental Setup}

Due to the scarcity of published results in multiphase fluid flow in networks, it is also important to consider the validity of the solutions obtained from the program developed here with the actual data network. To illustrate the steam distribution network program, the layout system installed on the steam network for Issran oil field is shown in Figure 6.

\subsection{Example}

Steam at 800 psi with $520 \mathrm{~F}$ and 0.8 quality is flowed through 4" in main stream pipes line at steam flow rate of $6000 \mathrm{~B} / \mathrm{D}$. Thus main stream pipes will divided to branches 3 " to complete network. Results parameters were listed for program solver and Issran actual data in Tables 2 and 3 respectively. Figure 7 and Figure 8 present steam pressure well head and the steam quality at well head found by the program solver and field reading.

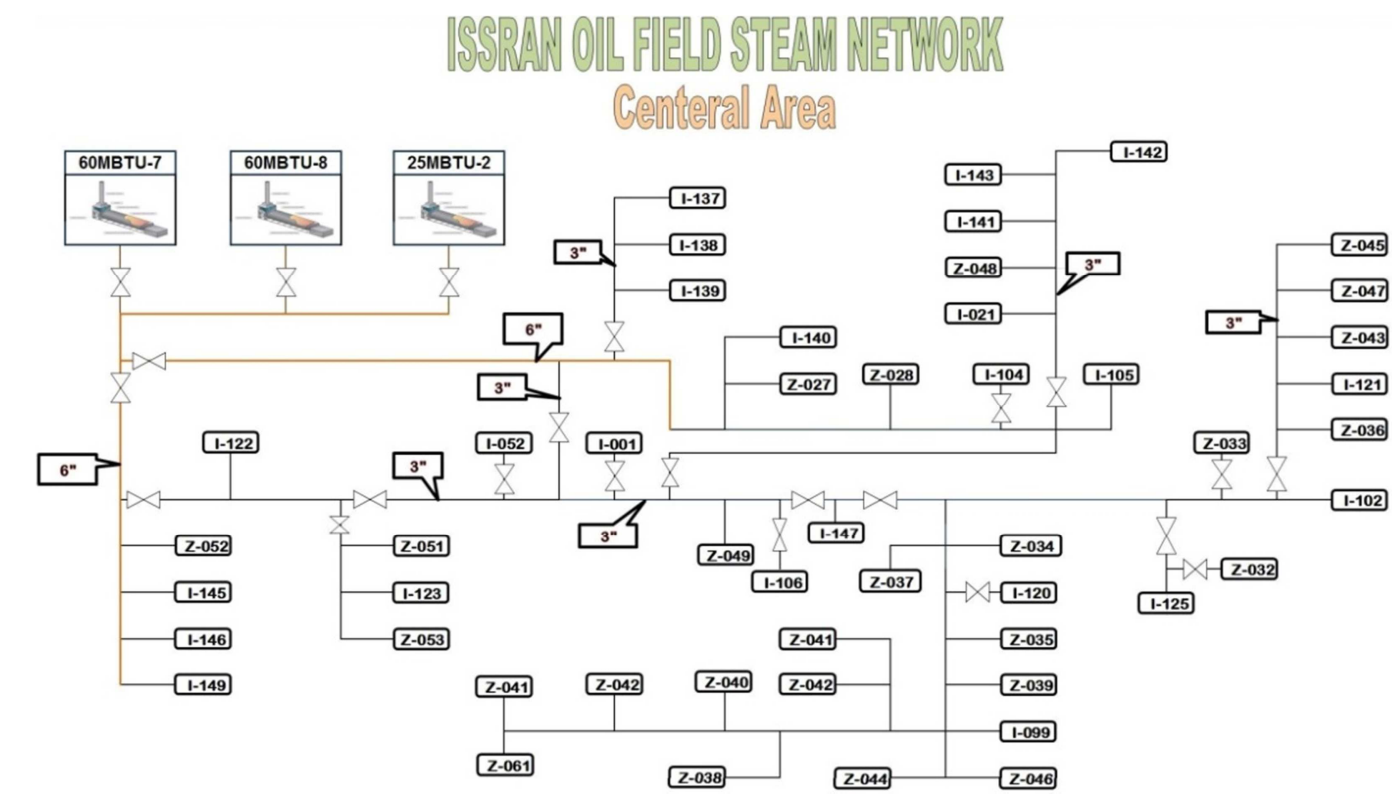

Figure 6. Issran steam injection field schematic steam distribution line.

Table 2. Case study, Results adopted on Simulation Program.

\begin{tabular}{llllllll}
\hline Wells & Diameter inch & Length M & Run Flow BWPD & Branch Flow BWPD & pressure psi & X1 \% & X3 \% \\
\hline 1 & 6 & 500 & 3800 & 1500 & 987 & 0.8 & 0.93 \\
2 & 6 & 800 & 2300 & 800 & 978 & 0.7 & 0.78 \\
3 & 6 & 1000 & 1500 & 400 & 973 & 0.66 & 0.6 \\
4 & 6 & 1500 & 1100 & 400 & 969 & 0.69 & 0.69 \\
5 & 6 & 1800 & 700 & 700 & 940 & 0.68 & 0.68 \\
C-23 & 3 & 200 & 1500 & 400 & 940 & 0.93 & 0.73 \\
C-28 & 3 & 400 & 1100 & 400 & 890 & 1 \\
C-037 & 3 & 600 & 700 & 400 & 850 & 1 \\
C-041 & 3 & 800 & 300 & 300 & 840 & 1 \\
C-169 & 3 & 300 & 800 & 500 & 956 & 1 \\
C-003 & 3 & 400 & 300 & 400 & 948 & 0.78 \\
C-002 & 3 & 300 & 400 & 400 & 973 & 0.43 & 0.43 \\
C-132 & 3 & 400 & 400 & 300 & 969 & 0.64 & 0.64 \\
Zs-006 & 3 & 300 & 700 & 400 & 900 & 0.69 & 0.69 \\
C-355 & 3 & 400 & 400 & & & 0.68 & 0.85 \\
\hline
\end{tabular}


Table 3. Case study, results adopted on real reading.

\begin{tabular}{|c|c|c|c|c|c|c|c|}
\hline Wells & Diameter inch & Length $M$ & Run Flow BWPD & Branch Flow BWPD & pressure psi & X1 \% & X3 \% \\
\hline 1 & 6 & 500 & 3800 & 1500 & 987 & 0.8 & 0.75 \\
\hline 2 & 6 & 800 & 2300 & 800 & 978 & 0.8 & 0.75 \\
\hline 3 & 6 & 1000 & 1500 & 400 & 973 & 0.8 & 0.75 \\
\hline 4 & 6 & 1500 & 1100 & 400 & 969 & 0.8 & 0.75 \\
\hline 5 & 6 & 1800 & 700 & 700 & 940 & 0.8 & 0.75 \\
\hline C-23 & 3 & 200 & 1500 & 400 & 960 & 0.8 & 0.75 \\
\hline C-28 & 3 & 400 & 1100 & 400 & 900 & 0.8 & 0.75 \\
\hline $\mathrm{C}-37$ & 3 & 600 & 700 & 400 & 890 & 0.8 & 0.75 \\
\hline C-41 & 3 & 800 & 300 & 300 & 880 & 0.8 & 0.75 \\
\hline C-169 & 3 & 300 & 800 & 500 & 960 & 0.8 & 0.75 \\
\hline C-37 & 3 & 400 & 300 & 300 & 950 & 0.8 & 0.75 \\
\hline C-2 & 3 & 300 & 400 & 400 & 960 & 0.8 & 0.75 \\
\hline C-132 & 3 & 400 & 400 & 400 & 940 & 0.8 & 0.75 \\
\hline Zs-006 & 3 & 300 & 700 & 300 & 930 & 0.8 & 0.75 \\
\hline C-355 & 3 & 400 & 400 & 400 & 925 & 0.8 & 0.75 \\
\hline
\end{tabular}

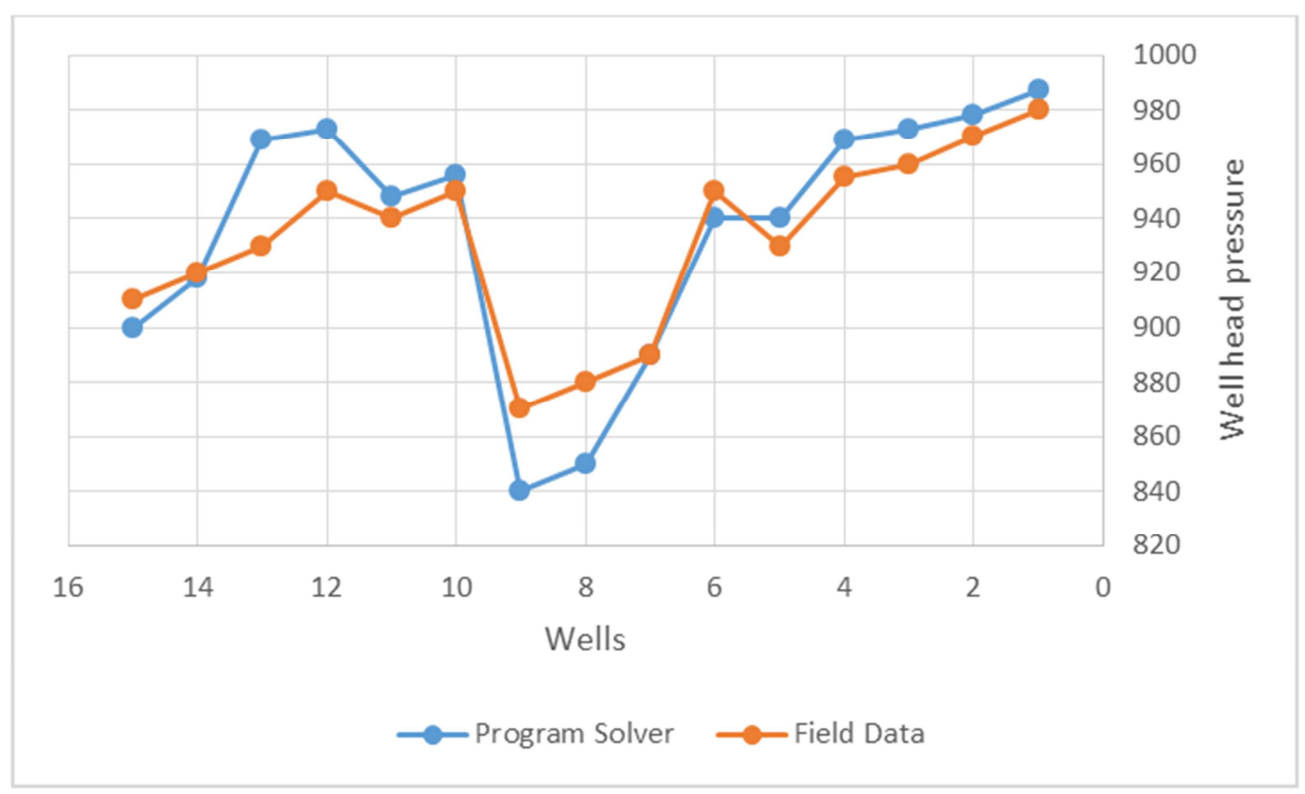

Figure 7. Well head pressure comparison between program solver results and actual data results.

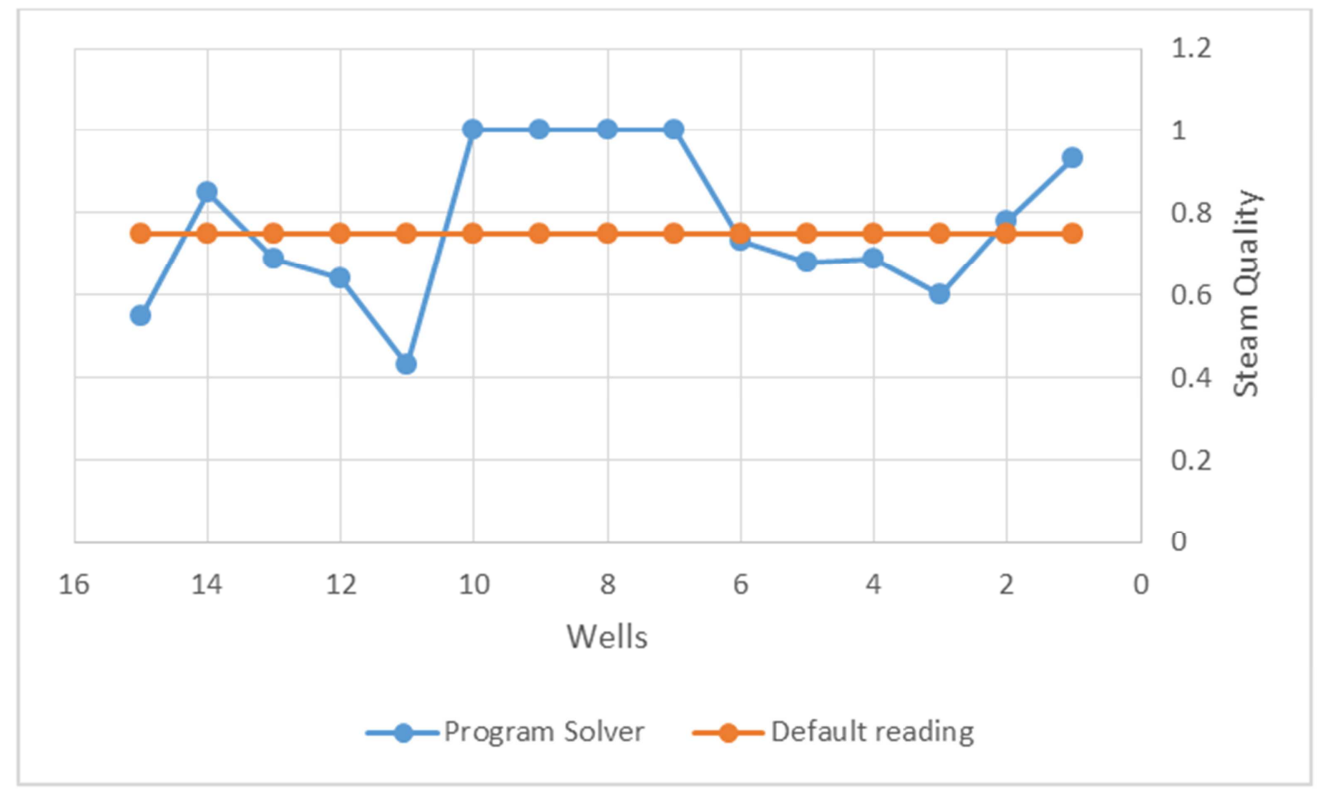

Figure 8. Comparison between program solver results of steam quality at well head and default data results. 


\section{Conclusion}

Controlling and monitoring of steam quality and steam flowrate in steam distribution network is very difficult. Simulation program have considered easy way to predict the steam quality at wellheads. Performed simulation program by MATLAB while took into account Tee-Junction effect depending on Seeger correlations. The program provides a dedicated graphical user interface (GUI) for operators to build the distribution network model easily and to visualize the simulation results. Thus, a computer program for simulating the behavior of a large steam injection network was developed. Required major factors to properly design a steam distribution system are Steam quality needed at wellhead, steam pressure in the reservoir, forecast of individual well injection rate, location and number of wells, timetable for injection rate or quality reduction, and future expansion requirements. Finally need more experimental investigation for Tee-junction to collect huge data bank.

\section{Nomenclature}

$\mathrm{a}=$ coefficient in Seeger et al.'s quality ratio equation

$\mathrm{g}=$ gravitational acceleration, $\mathrm{ft} / \mathrm{sec} 2$

$\mathrm{p} 1=$ steam pressure of the inlet stream, psig

$\mathrm{S} 1=$ velocity ratio in Seeger et al.'s correlation, dimensionless

$\mathrm{u} 1=$ mass flux of steam in the inlet stream, $\mathrm{Ibm} /\left(f t^{2}-\mathrm{s}\right)$

$\mathrm{u} 2=$ mass flux of steam in the run stream, $\mathrm{Ibm} /\left(f t^{2}-\mathrm{s}\right)$

$\mathrm{u} 3=$ mass flux of steam in the branch stream, $\mathrm{Ibm} /\left(f t^{2}-\mathrm{s}\right)$

ug $1=$ mass flux of vapor phase in the inlet stream,

$\mathrm{Ibm} /\left(f t^{2}-\mathrm{s}\right)$

ug2 $=$ mass flux of vapor phase in the run stream,

$\mathrm{Ibm} /\left(f t^{2}-\mathrm{s}\right)$

ug $3=$ mass flux of the vapor phase in the branch stream, $\mathrm{Ibm} /\left(f t^{2}-\mathrm{s}\right)$

$\mathrm{u} 2 / \mathrm{u} 1=$ mass-flux ratio of the run stream, dimensionless

$\mathrm{u} 3 / \mathrm{u} 1=$ mass-flux ratio of the branch stream, dimensionless

vf $1=$ specific volume of saturated liquid at the inlet pressure, $f t^{3} / \mathrm{Ibm}$

$\operatorname{vg} 1=$ specific volume of saturated vapor at the inlet pressure, $f t^{3} / \mathrm{Ib}$

$v 1=$ specific volume of steam at the inlet pressure, $f t^{3} / \mathrm{Ibm}$

$V^{*} g 1=$ critical velocity of saturated vapor at the inlet pressure, $\mathrm{ft} / \mathrm{sec}$

$\mathrm{Vg} 1=$ superficial vapor velocity at the inlet, $\mathrm{ft} / \mathrm{sec}$

$x 1=$ steam quality of the inlet stream, fraction

$x 2=$ steam quality of the run stream, fraction

$x 3=$ steam quality of the branch stream, fraction

$x 2 / x 1=$ quality ratio of the run stream, dimensionless

$x 3 / x 1=$ quality ratio of the branch stream, dimensionless $\sigma=$ interfacial tension, $\mathrm{Ibm} / \mathrm{sec}$

\section{References}

[1] P. S. Sarathi and D. K. Olsen. "Petroleum Reservoir Simulation". Applied Science Publishers, 1992.

[2] Michael. Prats.: "A Current Appraisal of Thermal Recovery". Society of Petroleum Engineers, 1986.

[3] L.W. Lake. "Enhanced Oil Recovery". Society of Petroleum Engineers, 1989.

[4] Tatsuro, Y. and Yukinori, K.:"Development of a Steam Distribution Network Simulator for Enhanced Oil Recovery Systems,"APCOM \& ISCM Singapore (2013).

[5] Ballyk, J.D., Shoukri, M., and Chan, A.M.C., "Steam-Water Annular Flow in a Horizontal Dividing T-Junction", International Journal of Multiphase Flow, Vol. 14, pp. 265$285,1988$.

[6] Sze-Foo Chien." Phase Splitting of Wet Steam in Annular Flow Through a Horizontal Branching Tee", SPE May 1996.

[7] Chien, S.F. and Rubel, M.T.:"Phase Splitting of Wet Steam in Annular Flow Through a Horizontal Impacting Tee, "SPEPE (Nov. 1992) 368-374.

[8] Collier, J.G.:"Single Phase and Two Phase Flow Behavior in Primary Circuit Components," Two-Phase Flow and Heat Transfer, Hemi-sphere Publishing, Washington, DC/1977) 1, 313-365.

[9] Hong, K.C., "Two-Phase Flow Splitting at a Pipe Tee", Journal of Petroleum Technology, Vol. 2, pp. 290-296, 1978.

[10] Azzopardi, B.J., and Whalle, PB.: 'The Effect of Flow Patterns on Tow-Phase Flow in a T-Junction," Intl.J.of multiphase Flow (1982) 8, 491-507.

[11] Seeger, W., Reimann, J., and Muller, U,:"Two-Phase Flow in T-Jnction With A Horizontal Inlet-Part I: Phase Separation,"Intl.J. of Multiphase Flow (1986) 12, 575-585.

[12] Lahey, R.T., "Current Understanding of Phase Separation Mechanisms in Branching Conduits", Nuclear Engineering and Design, Vol. 55, pp. 145-161, 1986.

[13] Azzopardi, B.J. and Hervieu, E., "Phase Separation at Junctions", Multiphase Science and Technology, Vol. 8, pp. 645-714, 1994.

[14] Azzopardi, B.J., "Phase Separation at T Junctions", Multiphase Science and Technology, Vol. 11, pp. 223-329, 1999.

[15] Azzopardi, B.J., Colman, D.A., and Nicholson, D., "Plant Application of a T-Junction as a Partial Phase Separator" Chemical Engineering Research \& Design, Vol. 80, pp. 87-96, 2002.

[16] Baker, G., Azzopardi, B.J., Clark, W.W., and Wilson, J.A., "Controlling the Phase Separation of Gas-Liquid Flows at Horizontal T-Junctions", AIChE Journal, Vol. 53, pp. 19081915, 2007.

[17] Doscher, T.M. and Huang, W.: "Steam Drive Performance Judged Quickly from Use of Physical Models," Oil \& Gas J. (Oct. 1979) 52. 
[18] J.W. Marx, R. H. Langenheim, " Reservoir Heating by Fluid Injection" Society of Petroleum Engineers. 1959

[19] T.C. Boberg, "Calculation of the Production Rate of a Thermally Stimulated Well". Society of petroleum Engineers. 1966.
[20] Gomaa, E.E.: "Correlations for Predicting Oil Recovery by Steam flood, JPT (Feb. 1980) 325. 